\title{
Historia de la chicha de uva: un producto típico en Chile
}

\author{
History of chicha grapes: a typical product in Chile \\ Pablo Lacoste ${ }^{1 *}$, Philippo Pszczolkowski ${ }^{2}$, Félix Briones ${ }^{3}$, \\ Paulette Aguilera ${ }^{1}$,Fernando Mujica ${ }^{4}$, Aldo Garrido ${ }^{1}$
}

\section{RESUMEN}

\begin{abstract}
El artículo examina la historia de la chicha, producto típico de Chile, cuyo origen se remonta a la colonia española. La chicha se obtiene a partir de la fermentación parcial del jugo de uva. Fue importante en la agroindustria chilena del siglo XVIII y alcanzó su apogeo en el XIX. Posteriormente, la chicha fue sustituida por los vinos con uvas francesas, sin embargo, se mantuvo como bebida arraigada en la población del campo y en las fiestas patrias chilenas. El texto analiza las características que tenía este producto, su ascenso y caída, junto con su actual pervivencia y reconocimiento oficial

Palabras clave: chicha cruda, chicha cocida, mosto de Vitis vinifera en proceso de fermentación, productos típicos, industria vitivinícola
\end{abstract}

\begin{abstract}
The article examines the history of chicha, a typical product of Chile, which dates back to the Spanish colony. The beer is obtained from the partial fermentation of the grape juice. It was important for the Chilean agribusiness eighteenth century and reached its apogee in the nineteenth. Later, chicha was replaced with French wine grapes. But it remained rooted drink the rural population and the Chilean national holiday. The article examines the characteristics that had this product, its rise and fall, along with their current survival and official recognition.
\end{abstract}

Key words: chicha, semi-fermented wort, typical products, wine industry.

\section{Introducción}

"La Presidenta de la República, Michelle Bachelet, ingresó a la elipse del Parque O'Higgins a bordo de un vehículo militar y en compañía del ministro de Defensa, Jorge Burgos, para encabezar la Parada Militar 2014 en la que participarán más de ocho mil efectivos de las Fuerzas Armadas y de Orden. Posteriormente, Juan González, presidente del Club de Huasos Gil Letelier, se acercó hasta la Presidenta para ofrecerle la tradicional chicha en cacho y brindar con ella por las Glorias del Ejército. Luego 20 parejas de la Agrupación de Teatro y Danza del Club, bailaron un pie de cueca frente a la tribuna oficial".

El Mercurio (Santiago), 19 de septiembre de 2014.
La chicha es un producto típico de la vitivinicultura popular del valle central de Chile. Se trata de una bebida de singular tradición, ampliamente difundida en las masas populares, sobre todo en las celebraciones de fin de cosecha, carnaval y fiestas patrias. Su legitimidad dentro de la cultura tradicional se refleja en el lugar de honor que tiene la chicha en la solemne fiesta nacional denominada "Gran Parada Militar en Honor a las glorias del Ejército", que el 19 de septiembre de cada año inaugura el Presidente de la República.

Esta bebida típica no ha sido estudiada hasta el momento con suficiente profundidad por la academia. Los trabajos de Claudio Gay (1855) trazaron un perfil un tanto despectivo de este producto y sentaron las bases de su valoración negativa, reiterada después por los autores posteriores (Couyoumdjian, 2006: 26-27; Del Pozo, 2014: 37-38). Algunos trabajos dedicados a la historia del vino chileno se han

\footnotetext{
Universidad de Santiago de Chile. Santiago, Chile.

Pontificia Universidad Católica de Chile. Santiago, Chile.

Universidad del Bío Bío. Concepción, Chile.

Escuela de Sommeliers de Chile. Santiago, Chile.

Autor por correspondencia: pablo.lacoste@usach.cl
} 
focalizado principalmente en las grandes viñas (Del Pozo, 2014), el problema del alcoholismo (Fernández Labbé, 2010) y el proceso de modernización impulsado por los franceses en la segunda mitad del siglo XIX (Briones; 2006; Couyoumdjian, 2006), el terroir y las cepas francesas (Pszczólkowski, 2004, 2013, 2014 y 2015). Naturalmente, estos autores se focalizaron en la corriente principal de la industria vitivinícola chilena, dejando para más adelante las ramas secundarias, dentro de las que se encuentra precisamente, la chicha.

Las referencias parciales de la literatura especializada en la historia del vino chileno, trazan algunos antecedentes para conocer este producto. Pero han dejado muchas preguntas abiertas. Por un lado, conviene identificar qué uvas se utilizaban para elaborar estos productos. Gay (1855) y Del Pozo (2014) los asocian con las uvas criollas, pero conviene definir con mayor claridad el concepto. Otro elemento que conviene aclarar es el ciclo histórico de este producto. Uno de los autores citados (Del Pozo, 2014: 39) reconoce como pioneros de la elaboración de chicha al santiaguino Pedro Ignacio del Villar (1735-1804). Otro estudio entrega datos de la rentabilidad económica de chicha por hectárea de viña en 1874 en Los Andes y San Felipe (Aránguiz, 1995). Queda pendiente sistematizar la información disponible, enriquecerla con nuevas fuentes y establecer con mayor precisión la historia, identidad y ubicación geográfica de estas bebidas, objetos del presente artículo.

En la actualidad, la chicha se elabora en Chile en el marco establecido por la ley 18.455 , reglamentada por Decreto 78 (1986) y Decreto 11 (2010). Alcanza un alto nivel de consumo en septiembre, en el marco de las fiestas patrias chilenas. Desde el punto de vista social, la chicha es interesante por su carácter artesanal: existen en Chile numerosos "chicheros", pequeños productores que se dedican, precisamente, a elaborar esta popular bebida, sin la amenaza de las grandes fábricas concentradas que monopolicen el mercado, como ocurre con la industria del vino. Se trata, por lo tanto, de un producto singular, que ha logrado mantener su identidad a lo largo de los siglos. El objetivo de este artículo es, precisamente, conocer esa historia.

\section{De la Chicha Indígena a la Chicha Chilena}

La elaboración de bebidas alcohólicas a partir de la fermentación era una costumbre arraigada en el sur de América antes de la llegada de los españoles. La modalidad más difundida era la chicha de maíz. Posteriormente, con la incorporación de las plantas europeas se extendió la costumbre de elaborar bebidas alcohólicas a partir de frutas, particularmente la uva. Así, por ejemplo, el diario El Comercio de Lima en abril de 1865 definía como chicha a la "bebida fermentada de maíz, arroz, piña y otras sustancias" (Rodríguez, 1875: 157). En las zonas andinas, el concepto de chicha permaneció asociado preferentemente a la bebida de maíz fermentado: "Bebida fermentada hecha de maíz, algarroba, uva, molle, chalchal, etc. La más común es el maíz" (Ozán, 2006: 200). Conceptos parecidos ofrece el Diccionario Folklórico Argentino (Coluccio, 1964).

Mientras en la región andina el concepto de chicha se mantuvo tradicionalmente asociado a la bebida de maíz fermentado, en Chile y Cuyo el término se comenzó a usar cada vez con más frecuencia para denominar una bebida obtenida de la fermentación de la uva. En su arribo, los españoles trajeron consigo distintas especies botánicas: "Muchas de ellas procedían de clima mediterráneo, por lo que encontraron en Chile condiciones ambientales ideales para su desarrollo. Así las disponibilidades de especies alimentarias aumentaron notablemente. Se preparó chicha de trigo y de cebada, de peras, membrillos, pero particularmente de uva... y de manzana..., cultivos que rápidamente se extendieron por el país" (Pardo y Pizarro, 2005).

El citado diario peruano El Comercio, en su nota de 1865 señalaba que en Chile se llamaba chicha a la bebida fermentada de uva, manzana y peras" (Rodríguez, 1875). Por su parte, el Diccionario de Regionalismos de provincia de San Luis entregaba la siguiente definición de chicha: "bebida espumante, no enteramente fermentada, hecha de uva pintona. Chicha de maíz: no se elabora más en la provincia" (Gatica, 1995).

Respecto de su elaboración, conocemos que en época precolombina el mapuche hacía fermentar la chicha en un tracal, especie de bolsa de cuero (probablemente camélido) que se amarraba a cuatro estacas que a su vez estaban enterradas en el suelo. Posteriormente, los españoles introducirán el uso del cuero de vacuno (Pardo y Pizarro, 2005). Esta preparación era una actividad exclusiva de la mujer, como lo señala el cronista colonial Alonso de Ovalle (Ovalle, 2003). El padre Rosales nos cuenta lo siguiente: "La chicha la hacen de todo 
género, como maíz, trigo, cebada, y de frutas como manzanas, peras, membrillos, frutillas, piñones, murtilla y de otras frutas particulares de la tierra" (Rosales, 1877).

Posteriormente, un estudio más amplio permitió una visión más completa del concepto:

"Bebida con uva y alcohol. Se elabora en las casas moliendo la uva y al zumo se le agregan unas manzanas en pedazos y unas hojas de albahaca. Se le coloca en un recipiente de cobre o hierro y se le hace hervir y se espuma; se retira, se deja enfriar $y$ se coloca en un recipiente de madera (tina). Se deja allí pudiendo tomarla una vez fría o dejarla unos dos o tres días que empiece a fermentar, tomando un sabor picantito y haciendo efervescencia. Bebida refrescante y que se obtiene de la uva fermentada, en vasijas de barro o madera. Bebida semifermentada con perfume a albahaca". (González, 2006).

La diversidad de las definiciones de "chicha" refleja su carácter popular y artesanal. Desde las culturas precolombinas hasta la actualidad, la chicha ha acompañado la vida social y cultural de los pueblos del sur de América, por medio de distintas modalidades. Una de ellas fue, precisamente, la chicha de jugo de uva, la cual alcanzó su máximo desarrollo en Chile.

\section{Chicha de Uva: Cruda y Cocida}

Los suelos de Chile y su clima mediterráneo facilitaron la propagación de la vid en los siglos XVII y XVIII. En esta centuria, Chile se convirtió en el mayor viñedo de América. En este contexto de abundancia de vid se produjo una evolución natural de la chicha hacia el mosto de uva. Y pronto surgieron especializaciones, principalmente a partir de la diferenciación entre chicha cruda y chicha cocida, división establecida con claridad en el siglo XIX y mantenida hasta la actualidad (decreto 71 del 31 de julio de 1986).

La chicha cruda tiene una elaboración muy sencilla. El mosto se hace fermentar, pero solo parcialmente. Solo una parte del azúcar de la uva se transforma en alcohol. Se obtiene por lo tanto un caldo muy dulce y de baja graduación alcohólica. Este producto, llamado chicha cruda, solo se consume durante el período de vendimia (marzo-abril en el hemisferio sur).

Más compleja es la elaboración de la chicha cocida. El método ha variado a lo largo del tiempo. En la actualidad, la chicha cocida se elabora a partir de mosto en torno a una densidad de $1.090 \mathrm{a} 1.110 \mathrm{~g} / \mathrm{l}$ (se alcanza en marzo-abril dependiendo de la zona). En envases de cobre se hace hervir en mezcla con cenizas de sarmientos que aportan carbonatos que neutralizan la alta acidez producida al concentrarse el volumen durante el proceso de ebullición; como alternativa puede usarse hoy directamente carbonato de calcio. Luego se elimina la espuma con un colador de crin de caballo (o bien de plástico). El proceso se detiene a 1.130-1.135 g/l. Después se envasa en barricas de 225-500 litros o tinajas de greda bien tapadas con barro. Las barricas o tinajas se acopian enterradas en el piso o lugares muy frescos. En los primeros días de septiembre, la chicha cocida se fracciona en botellas, generalmente del tipo usado para vinos espumosos, que se obturan con corchos amarrados para evitar que la presión interna los expulse. El producto queda listo para su distribución y consumo en las fiestas patrias del 18 de septiembre.

Las publicaciones agrícolas del siglo XIX recogieron el interés de la industria por la chicha, y elaboraron un enjundioso artículo en el cual se reflejaban los sistemas empleados en la época. Así se reflejó en el artículo de Solar y Claro "Fabricación de la Chicha cocida", publicado por el Boletín de la Sociedad Nacional de Agricultura (Solar y Claro, 1890).

Como todo producto vitivinícola, la buena chicha dependía de la uva y del sistema de elaboración. La influyente publicación sostenía que "las mejores uvas son las blancas; de estas podemos preferir los moscateles, la torrontés, malvasía, la pinot, la semillón. Se puede fabricar chicha con uvas negras pero hay que operar con mucho cuidado porque tiñen el caldo" (Solar y Claro, 1890).

De acuerdo con este artículo había dos tipos de chicha según su ciclo: 1) chicha fuerte: de venta inmediata y tiene una duración de 4 a 6 meses; y 2) chicha de guarda larga: de 4 a 6 años. La chicha fuerte se destinaba para su venta inmediata. En su elaboración, durante el cocimiento, se realiza una concentración acotada, "hasta alcanzar $14^{\circ}$ de intensidad y $22^{\circ}$ de azúcar. Pesado caliente el líquido, el glucómetro marca $2^{\circ}$ de densidad y $1^{\circ}$ de azúcar menos que pesado en frío" (Solar y Claro, 1890 ). La chicha de guarda, en cambio, requiere mayor 
elaboración. Su concentración es más avanzada y debe llegar hasta que el glucómetro o pesa mosto marque en frío $17^{\circ}$ de densidad y $26^{\circ}$ de azúcar. En el proceso de fermentación se van a implementar métodos distintos para obtener chicha de guarda corta o larga.

La fermentación también es diferente. La fermentación de la "chicha fuerte" se realiza en cubas de 600 litros; al segundo o tercer día comienza la fermentación tumultuosa, que se prolonga de 15 a 20 días. Luego, la chicha se deja en las cubas durante 25 a 40 días para que las borras se asienten. Con posterioridad se lleva a las barricas, previamente azufradas. Allí "se deja reposar unos cuantos días hasta que aclara un poco, al cabo de los cuales se trasiega a barricas, que deben estar azufradas. Entonces ya está en estado de entregarla al comercio" (Solar y Claro, 1890).

Algo diferente era la fermentación de la "chicha de guarda". En primer lugar, se realiza una tarea lenta de asentamiento de borras. Luego se inicia la fermentación, pero en recipientes más pequeños (barricas de 200 litros). Se deja un espacio vacío, sin líquido (10 litros) "para evitar los derramas que produciría la fermentación tumultuosa. Para apretar los barriles hay que esperar que pase completamente la fermentación" (Solar y Claro, 1890). Diariamente debía realizarse el relleno de la barrica, dejando siempre un espacio vacío. "Una vez que ha pasado completamente (la fermentación tumultuosa) se rellena bien cada seis u ocho días" (Solar y Claro, 1890). El trasiego es otro trabajo importante en la elaboración de la chicha de guarda. Tiene como objetivo retirar la borra y preservar la calidad del producto. Se debe realizar un trasiego cada dos meses a lo largo de todo el período de guarda de la chicha. Después del segundo trasiego se debe aumentar el grado alcohólico de la chicha hasta llegar entre $14^{\circ}$ y $17^{\circ}$, para lo cual se agrega alcohol puro de uva. "Mientras mayor grado de alcohol tenga la chicha, menos expuestos estamos a perderla y durará mucho más" (Solar y Claro, 1890).

Este proceso demora la expedición del producto al mercado, pero es indispensable para preservar su calidad: "Hay muchos que creen que la chicha está en estado de ser entregada al consumo después de este (segundo) trasiego; pero es un error, porque está imbebible por lo dulce. Hay que esperar para venderla, unos 18 o 24 meses. Una chicha bien cuidada dura cuatro a seis años; pero no es económico guardarla tanto tiempo" (Solar y Claro, 1890).
La clarificación era otro aspecto decisivo en la calidad y el valor de mercado de la chicha. Las chichas turbias se vendían entre 25 y 30 centavos; en cambio las chichas con buena clarificación se valuaban entre 40 y 50 centavos. Para bajar costos, algunos preferían filtrar en vez de clarificar la chicha; pero el resultado era muy distinto. "Una chicha filtrada se presentará clara, a lo más, durante un mes, mientras que una clarificada será siempre clara. Esto proviene de que la filtración no quita toda la borra" (p. 1064). Para realizar la clarificación se recomendaba utilizar gelatina o clara de huevo. La gelatina se vendía en panes de 30 gramos cada uno; su valor de mercado era de entre $\$ 7$ y $\$ 8$ por kilogramo. Se recomendaba utilizar $1 \frac{1 / 2}{2}$ pan de gelatina (45 gramos) para cada barrica de 220 litros de chicha. Si en vez de gelatina se usa clara de huevo, la proporción recomendable era de dos claras cada 35 litros de chicha. La clarificación se demora de 25 a 35 días. Cuando esté completamente clarificada se trasiega a otra barrica" (Solar y Claro, 1890).

El uso de azufre en las cubas y barricas era uno de los pilares de la elaboración de la chicha. El anhídrido sulfuroso que se produce con la combustión del azufre tiene la propiedad de detener la fermentación alcohólica; "por consiguiente, mientras más tiempo se quiera conservar una chicha, mayor será la cantidad de azufre que se le deba quemar a las barricas" (Solar y Claro, 1890). Mientras mayores son las dosis de anhídrido sulfuroso aumenta el etanal, sulfuroso combinado y sulfitos, estos últimos producen efectos alérgicos en algunas personas.

Las normas que se usaban para elaborar chicha en Chile a fines del siglo XIX reflejan el ingenio de los chicheros artesanales para, con capitales acotados, obtener un producto interesante, capaz de seducir a los mercados y nutrir el alma popular de Chile.

\section{Origen y Apogeo de la Chicha de Uva en el Valle Central}

La producción de chicha como producto de consumo masivo en Chile está documentada desde mediados del siglo XVIII. Un documento del 15 de abril de 1760, elaborado por el Cabildo de Santiago, entrega noticias sobre los efectos de este licor en la población de la época: "Se experimentan muchas muertes y desgracias con motivo de un licor a quien le dan el nombre de chichita, el cual causa en el que 
lo toma dos perniciosos efectos: el uno, que al que lo encuentra con alguna debilidad le quita la vida, fermentando en el estómago lo que no hizo en la vasija, por no darle quien le ha dado el nombre de chichita; el segundo efecto es aquel que causa en los más robustos, que poniéndose cuasi ebrios o desalentados y calentones como ellos mismos dicen, arman mil pendencias y disgustos que resultan en muchos desacatos" (Pereira, 2013).

La producción y comercialización de chicha se popularizó en Chile entre los siglos XVIII y XIX. Poco a poco, los inventarios de bienes levantados por los notarios dieron cuenta de este proceso. Así, por ejemplo, en Colchagua, tras el fallecimiento de Ramón Ramírez, en su tasación de bienes (1823) se documentaron 25 arrobas de chicha, tasada a 10 reales la arroba. ${ }^{1}$ Hacia 1837, don Francisco Prats, propietario de una viña de 11.000 plantas, tenía en su bodega 457,5 arrobas de chicha, valuada a 71/2 reales cada arroba; mayor valor tenía su sancochado: las ocho arrobas de este licor se tasaron a $\$ 3$ por arroba. ${ }^{2}$ Poco después se documentó chicha en la chacra de Miraflores (Ñuñoa), propiedad de don Alejo Lemus. En 1842 se elaboraron 100 arrobas de chicha, tasadas a 12 reales la arroba; al año siguiente también se obtuvo chicha, aunque en menor cantidad (solo 50 arrobas) y a un precio algo menor (10 reales por arroba). Luego, en 1844, la cantidad de chicha elaborada volvió a subir hasta las 100 arrobas, aunque el precio se mantuvo en 10 reales por arroba. ${ }^{3}$

La producción y consumo de chicha elaborada a partir de la uva con fermentación incompleta, se difundió ampliamente en Chile, entre Santiago y Concepción. El valle central fue el centro de esta tradición, que acompañó al pueblo chileno durante los siglos XIX y XX.

En el siglo XIX se produjo el apogeo de la producción y consumo de chicha en Chile. La expansión de la economía en general, facilitada por la multiplicación de los ferrocarriles y la ampliación del comercio, generó las condiciones para que la chicha lograra niveles sin precedentes. La producción se incrementó hasta niveles nunca registrados en Chile. La chicha ocupó un lugar central en la agroindustria nacional.

Muchos viticultores chilenos destinaban una parte de la uva a la elaboración de chicha. Fácil consumo, rápida venta y bajo costo alentaba a sostener esta actividad. Grandes cantidades de chicha se elaboraban y consumían cada año en
Chile, sentando así las bases de una profunda tradición popular.

El Estado ordenó levantar datos permanentemente sobre las cantidades de producción de chicha. El análisis de estos relevamientos muestra que los viticultores chilenos dedicaron una parte sustancial de sus energías productivas a esta bebida. En efecto, la producción anual de chicha llegaba muy cerca de la producción de vinos y mostos. Así se desprende de los Anuarios del Instituto Nacional de Estadística (INE), entre 1861 y 1890 (Tabla 1).

La información del cuadro muestra la relevancia relativa de este producto en el contexto general de la industria vitivinícola de Chile. La chicha era un producto muy popular. Como se obtenía de la fermentación parcial del mosto, este producto tenía una graduación alcohólica inferior al vino (en la actualidad la relativamente baja graduación alcohólica de la chicha es solo aparente, ya que la ley considera el grado potencial que es igual a alcohol más azúcar y este debe ser igual al del vino, al menos $11,5^{\circ} \mathrm{gl}$ ). Por lo tanto, se podía beber en mayores cantidades. Era ideal para las fiestas y celebraciones. Por otra parte, su baja graduación alcohólica determinaba una corta vida útil. En pocos días, la chicha se deterioraba; por lo tanto, debía consumirse en un plazo relativamente breve.

Estos productos se destacaban no solo por el volumen de producción, sino también por su voluntad de alcanzar mejores niveles de calidad, presentarse y competir en las exposiciones de la época. En efecto, en la segunda mitad del siglo XIX, a pesar del desprecio generado por las élites intelectuales y los tecnócratas, los productores de estos productos típicos lograban destacarse en las competencias. Por ejemplo, en la Exposición Departamental de Los Andes, en el Tercer grupo, letra C.- Chichas, aparecen las chichas con veinticuatro exponentes, que merecieron un primer premio, un segundo y tres menciones honrosas. (Le Feuvre, et al., 1886).

La importancia del consumo de estos productos queda de manifiesto en los avisos comerciales publicados en la segunda mitad del siglo XIX. Los productores de chicha elaboraban sus avisos comerciales con ideas ingeniosas y originales. $\mathrm{Si}$ se trataba de "conseguir larga vida", había que ir al acreditado despacho de chicha de la casa de don Manuel García (Dussaillant, 1993, 152). Entre 1860 y 1930 la chicha ocupó un lugar destacado en las páginas comerciales de la prensa chilena. Los 
Tabla 1. Producción vitivinícola de Chile (1861-1890) (en litros).

\begin{tabular}{|c|c|c|c|}
\hline Año & CHACOLÍ & CHICHA & VINO Y MOSTO \\
\hline 1861 & 10.121 .938 & 18.189 .127 & 25.015 .786 \\
\hline 1862 & 15.185 .622 & 20.972 .512 & 26.232 .228 \\
\hline 1863 & 12.719 .615 & 24.846 .595 & 21.741 .585 \\
\hline 1864 & 15.830 .941 & 27.062 .207 & 26.912 .444 \\
\hline 1865 & $\mathrm{~s} / \mathrm{d}$ & $\mathrm{s} / \mathrm{d}$ & $\mathrm{s} / \mathrm{d}$ \\
\hline 1866 & 15.830 .941 & 22.793 .839 & 25.329 .676 \\
\hline 1867 & 16.353 .643 & 23.684 .359 & 28.640 .584 \\
\hline 1868 & 16.232 .839 & 24.253 .564 & 23.501 .926 \\
\hline 1869 & 18.012 .878 & 21.217 .071 & 23.129 .635 \\
\hline 1870 & 14.449 .285 & 23.311 .897 & 20.582 .015 \\
\hline 1871 & 14.192 .659 & 23.311 .897 & 25.974 .429 \\
\hline 1872 & 20.685 .744 & 20.140 .853 & 31.327 .579 \\
\hline 1873 & 21.458 .295 & 21.279 .906 & 32.131 .689 \\
\hline 1874 & 19.668 .207 & 20.702 .961 & - \\
\hline 1875 & 21.552 .121 & 20.157 .148 & 29.658 .805 \\
\hline 1876 & 20.044 .152 & 25.812 .588 & 26.511 .720 \\
\hline 1877 & 20.024 .726 & 20.391 .191 & 20.507 .325 \\
\hline 1878 & 18.340 .156 & 17.780 .576 & 24.701 .685 \\
\hline 1879 & 19.319 .070 & 18.206 .165 & 21.796 .483 \\
\hline 1880 & 28.059 .418 & 20.215 .595 & 19.454 .716 \\
\hline 1881 & $\mathrm{~s} / \mathrm{d}$ & $\mathrm{s} / \mathrm{d}$ & $\mathrm{s} / \mathrm{d}$ \\
\hline 1882 & 17.680 .558 & 19.568 .142 & 28.659 .515 \\
\hline 1883 & 22.825 .284 & 21.994 .551 & 38.780 .905 \\
\hline 1884 & 19.675 .158 & 22.800 .150 & 27.628 .947 \\
\hline 1885 & 17.449 .366 & 18.490 .473 & 28.949 .084 \\
\hline 1886 & 15.239 .653 & 17.529 .216 & 27.636 .753 \\
\hline 1887 & 12.292 .129 & 12.992 .462 & 20.843 .680 \\
\hline 1888 & 11.152 .403 & 12.036 .735 & 21.236 .214 \\
\hline 1889 & 5.802 .434 & 7.148 .815 & 12.375 .129 \\
\hline 1890 & 9.349 .345 & 10.471 .621 & 17.579 .835 \\
\hline Total & 487.229 .137 & 561.362 .216 & 676.840 .172 \\
\hline
\end{tabular}

Fuente: Anuario Estadístico de la República de Chile, 1861-1890.

productores, distribuidores y comerciantes libraron auténticas batallas de ideas, diseño e ingenio para promover este producto y captar la atención de los clientes. Algunos avisos destacaban las cualidades de la chicha para la salud (mejorar la digestión, evitar la flatulencia). Otros enfatizaban el placer de su consumo (sabor, aroma, perfume). En algunos casos se ponía el foco en la procedencia geográfica, sobre todo la chicha del Aconcagua y la chicha de Valdivia, o bien, los galardones obtenidos en las Exposiciones Universales. Fue también un proceso de desarrollo de la publicidad gráfica, con audaces diseños. La notable cantidad y calidad de los avisos comerciales, clasificados y económicos de la chicha en ese período, constituye un corpus documental cuyo análisis escapa a los objetivos del presente artículo. Basta por ahora señalar que la prensa gráfica fue un notable medio para difundir, extender y consolidar el mercado de la chicha en Chile.

\section{Los Tecnócratas Europeos y el Desprecio hacia estos Productos Típicos}

Los tecnócratas europeos lideraron la transformación de la viticultura chilena en la segunda mitad del siglo XIX. Revestidos del prestigio que irradiaban sus países de origen, lograron posicionarse en el centro de la formación de opinión sobre la valoración de los productos del campo y la jerarquía de los alimentos en todo el país. Ellos realizaron sus acciones en un ambiente sociocultural de admiración ilimitada de las élites chilenas (como ocurrió en el resto de América Latina) por la cultura europea en general 
y francesa en particular. En este contexto, ellos gozaron de un poder y una influencia decisivos en el proceso de modelar los gustos y tendencias. Tanto Claudio Gay (1865) como René Le Feuvre (1877 y 1890), Julio Menadier (1874), Riveros (1881) y Charlin (1881) participaron de esta corriente. Ellos dirigieron institutos de formación técnica y publicaciones especializadas desde donde marcaron una línea de pensamiento que se convirtió en hegemónica. Las élites adoptaron los criterios propuestos por estos tecnócratas, lo que se hizo notar en la vida económica, comercial y cultural, particularmente en las pautas de consumo de alimentos y bebidas.

En el plano de la vitivinicultura, los tecnócratas europeos instalaron dos tendencias: por un lado, la sobrevaloración de las cepas francesas y los vinos imitación, tipo Burdeos, Borgoña, Champagne, etc. Por otra parte, esta tendencia se vio acompañada con una actitud de desprecio hacia las variedades de uva criollas (uva país, moscatel de Alejandría, moscatel amarillo (Torrontés), moscatel de Austria, entre otros. Para aquellos tecnócratas, esas variedades no tenían valor enológico; no era posible elaborar con ellas vinos de buena calidad. Instalaron una cultura de la minimización del valor de las variedades criollas, concepto que se transformó en paradigma hegemónico en las ciencias agrarias chilenas, y mantuvo esta posición durante más de un siglo. Recién se comenzaría a revertir a comienzos del siglo XXI, con exitosos ensayos de vinos, espumantes y piscos de uva país y moscatel de Alejandría.

Además de despreciar las variedades criollas, los tecnócratas europeos del siglo XIX despreciaron la viticultura tradicional en su conjunto. En lugar de valorar la diversidad de métodos y estilos, propiciaron que solo era aceptable la aplicación de los sistemas franceses. Negaron el valor de las viñas de rulo y las cepas de cabeza. También censuraron el equipamiento y las instalaciones de los viticultores artesanales, como lagares de cuero y pipas de roble chileno. Finalmente, negaron todo valor a los productos típicos como pipeño, chicha, chacolí y asoleado. En líneas generales, para estos autores, estos productos eran de mala calidad por provenir de viñas mal cultivadas y usar deficientes métodos de elaboración, particularmente la chicha y el chacolí (Le Feuvre, 1884: 335). Los textos dedicados a analizar la situación del agro chileno y recomendar cambios para el "mejoramiento" de la industria insistían en cuestionar estos productos:

"Los productos más comunes de nuestros viñedos: las chichas y los chacolíes son de tan imperfecta elaboración que por su mala calidad y aun por su insalubridad debieran proscribirse en lugar de permitir que cada año se aumente su producción y consumo" (Menadier, 1874).

El repetido martilleo de los tecnócratas extranjeros se extendió también a los enólogos y agrónomos chilenos. Los manuales de estudio y los centros de enseñanza, al tratar los temas de viticultura y vinificación, terminaron por consolidar el paradigma afrancesado propuesto. Como resultado, en el siglo XX se impuso en la viticultura chilena una tendencia a reproducir el modelo de las viñas centradas en variedades francesas, con métodos franceses, adaptados al estilo de las grandes fábricas de vino, en manos de un reducido número de familias ricas.

Hasta fines del siglo XIX, la producción de los vinos típicos seguía siendo importante, pero a partir de entonces comenzó a perder terreno frente al avance de los vinos al estilo francés. En 1883 se producían en Chile 41,7 millones de litros de vino contra 40 millones de litros de chicha y 31 millones de chacolí; en 1923, las cifras eran de 243 millones de litros de vino contra 32 y 57 millones para la chicha y el chacolí, respectivamente (Del Pozo, 2014).

Las décadas de 1850,1860 y 1870 fueron una fase de transición, en la cual como vemos, el vino país así como el chacolí y el aguardiente era expuesto en el mismo escenario con el vino "de imitación francesa" que estaba lejos de predominar. En efecto, según cifras de 1869, la casi totalidad del vino producido en Chile era el del primer tipo que alcanzaba a 651.000 arrobas o 25 millones de litros, de los cuales casi la mitad se producían en Concepción, con 250.000 arrobas, seguida de Maule con 113.000; Santiago solo rendía 19.000 arrobas. Del "vino Burdeos", del que se hacía contabilidad aparte, solo se habían producido 22.800 arrobas, casi todas en Santiago. La producción de chicha y de chacolí seguía siendo muy importante, con cifras de 624.000 y 507.000 arrobas, la mitad de lo cual se producía en Santiago (Del Pozo, 2014). 


\section{La Tradición Presidencial de la Chicha en Cacho}

En el siglo XX, con el avance del proceso de industrialización, el auge de las grandes fábricas de vino y la concentración en grandes grupos económicos, la vitivinicultura chilena tomó otros rumbos. La corriente principal quedó en manos de productos elaborados al estilo francés, con cepas francesas, y métodos de esa tradición. La chicha, como otros productos típicos chilenos, perdió el lugar central que había ocupado en la producción y el consumo. La chicha se mantuvo en la última centuria como un producto principalmente de interés artesanal. La tradición la mantuvo viva el pequeño viticultor de zonas típicas como San Javier, Villa Alegre, Curacaví y otras zonas rurales del valle central, de fuertes tradiciones huasas. Mientras en las grandes ciudades los mercados se reorientaban hacia nuevas pautas de consumo, fuertemente influidos por las campañas publicitarias y los circuitos de distribución y promoción, para alejarse de la chicha, esta se mantenía viva en el Chile profundo, en las localidades campesinas. Allí se conservó la valoración de este producto, sobre todo para consumir la chicha cruda en época de vendimia, y la chicha cocida en las fiestas patrias de septiembre.

Fueron justamente los campesinos quienes, en el segundo tercio del siglo XX, lograron romper el aislamiento de la chicha, y conectarla nuevamente con el centro del poder simbólico de Chile, al menos un día al año, en la celebración oficial del Día de las Glorias del Ejército de Chile. El primer paso fue la incorporación de los huasos a esta fiesta; su ingreso al protocolo oficial y al escenario central de la celebración. Ello ocurrió en la parada militar del 19 de septiembre de 1931, presidida por el vicepresidente, en función como presidente interino, Manuel Trucco Franzani (3 de septiembre a 15 de noviembre de 1931), la que contó con la primera participación de un grupo de huasos. En ella desfiló un escuadrón ataviado con ponchos provenientes de diferentes barrios de Santiago, principalmente del sector Matadero. ${ }^{4}$ A partir de ese año, los huasos lograron asentar su presencia en estas celebraciones, lo que significaba una reivindicación de su relevancia como parte importante de la nación. No es casual la fecha: se trata de la primera celebración después de la Gran Depresión económica mundial de 1930, la cual significó el cierre del paradigma del desarrollo hacia fuera, y el inicio de una nueva etapa en la historia económica y social de Chile, más orientada hacia el desarrollo hacia dentro. Se terminaba entonces la confianza en el progreso indefinido a partir de los modelos promovidos por Francia y Gran Bretaña y la escuela económica clásica. Ante la más aguda crisis económica que se registraba en la historia de Chile, las grandes potencias no aportaban ayuda significativa y el país sintió que debía arreglárselas solo. Por eso, se abrieron oportunidades para volver a valorar lo propio, lo nacional, lo tradicional. Y justamente en este contexto se les abrió la posibilidad de incorporar a los huasos en la Parada oficial de septiembre. No es casualidad que eso haya ocurrido ese año, el mismo en el cual meses antes el Presidente Carlos Ibáñez del Campo (10 de mayo de 1927 a 3 de septiembre de 1931) tomó la decisión de delimitar la Denominación de Origen Pisco, la más importante de América del Sur en el momento actual.

Con el pasar de los años, la presencia de los huasos en el desfile oficial se consolidó. Hasta que se generaron las condiciones para el siguiente paso: en 1948, siendo Presidente Gabriel González Videla, previo al inicio de la parada militar de ese año, el huaso a caballo don Enrique Quintero se acercó a la tribuna oficial y ofreció al presidente un cacho de chicha baya diciendo: "A nombre de todos los huasos de Chile le ofrezco este trago presidente". ${ }^{5}$ Gabriel González Videla agradeció el gesto y bebió del cacho de chicha; el cual estaba adornado artísticamente. ${ }^{6} \mathrm{El}$ gesto del huaso al ofrecer el cacho, y del presidente, al beberlo, significaron una ruptura inesperada del protocolo, situación usualmente mal vista en un país tan formal como Chile. Sin embargo, en esta situación, el efecto fue exactamente inverso: el público expresó fervorosamente su aprobación por el gesto, debido a la identificación profunda que tenía con el típico producto del campo chileno. En los años subsiguientes, mientras se mantuvo como presidente de Chile, reiteró estas acciones, para sentar así las bases de una tradición. En 1950 la prensa celebró esta actitud, catalogando la acción como "democrático rasgo". ${ }^{7} \mathrm{Al}$ año siguiente, como la práctica ya estaba consolidada, los huasos se prepararon con más esmero, y el cacho de chicha fue adornado con los colores de la bandera chilena. Así lo recibió el Presidente González Videla y, tras

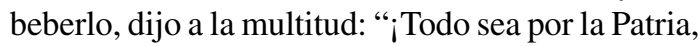
así tiene que ser la cosa!". ${ }^{8} \mathrm{Al}$ año siguiente, Videla cumplió su mandato constitucional y dejó el poder 
a su sucesor. La tradición ya estaba consolidada y, como ha reflejado el epígrafe inicial de este artículo, se mantiene vigente en la actualidad.

\section{Conclusión}

La chicha emerge como una singular bebida del valle central de Chile, profundamente arraigada en la cultura nacional, en la vida social y económica. Lejos de los glamorosos salones de los vinos de élites, la chicha ha logrado consolidarse como un producto cultural propio de Chile. Uno de los elementos propios de la chicha es un carácter mestizo, pues tiene sus raíces en la tradición indígena de elaborar bebidas alcohólicas mediante la fermentación de vegetales, sobre todo frutas y maíz. Estas prácticas continuaron después de la conquista con la incorporación de la uva, traída por los españoles en el siglo XVI. Poco a poco, la chicha de uva se consolidó en el centro de la vida social del pueblo chileno. En el siglo XVIII la chicha ya representaba una rama dinámica de la producción, el consumo y el comercio de bebidas alcohólicas en Chile. Esta tendencia se consolidó en el siglo XIX, cuando alcanzó su período de apogeo.

La documentación relevada muestra que la chicha no era un producto improvisado ni simple. Por el contrario, había normas para su elaboración. Por lo general se recomendaba elaborarla a partir de uvas criollas blancas, sobre todo moscateles, moscatel de Alejandría y torrontés. La fermentación se realizaba en forma incompleta, mediante el azuframiento de las barricas. La combustión química del azufre, formando anhídrido sulfuroso, contribuye a interrumpir la fermentación y asegurar así la identidad y originalidad de la chicha. Además, había dos variedades: chicha fuerte o cruda, y chicha de guarda o cocida, esta última de mayor costo y precio superior.

Hacia fines del siglo XIX, la chicha alcanzó su punto de apogeo. Posteriormente comenzó a declinar, debido a las fuertes críticas que sufrió como resultado de la posición hegemónica que alcanzaron las representantes de la viticultura francesa. Poco a poco, las élites comenzaron a abandonar y menospreciar el valor de la chicha, para pasarse a consumir bebidas europeas y vinos de uvas francesas. De todos modos, el pueblo chileno mantuvo viva la tradición del consumo de la chicha. A partir de 1948 se ha consolidado la tradición de valorar la chicha desde la cúspide del poder institucional del Estado. Así se refleja en la degustación de chicha en cacho del Presidente de la República, el día de las Glorias de Chile. Por medio de este portal, la chicha ingresa en una semana de amplia popularidad, en las fondas de la semana del 18 de septiembre en Chile. Pasado este lapso, el furor de la chicha se calma, pero se mantiene parcialmente latente hasta el año siguiente, en modalidades específicas, como en modalidades específicas, como bebida que ha logrado un renovado lugar en el folklor nacional.

\section{Agradecimientos}

Los autores agradecen al proyecto Fondecyt 1130096 "Denominaciones de Origen e identidad de vinos y agroalimentos en Chile, financiado por CONICyT.

\section{Literatura Citada}

Aránguiz, D. H.; Rodríguez Salas, C.

1996. Tradicionalismo y cambio agrícola en Aconcagua: elementos para su comprensión. Historia, 29: 29-33.

Castro, A.

2014. Curar penas, alegrar el alma. Alcohol y vino en los relatos campesinos chilenos. Revista Iberoamericana de Viticultura, Agroindustria y Ruralidad (RIVAR), 1 (1): 57-74.

Charlín Recabarren, J.

1881. Memoria sobre el fundo Porvenir de Huechagüe, perteneciente a los señores Espinoza y Fernández, sito en el Departamento de Cauquenes. Manuscrito. Santiago, Chile.

Coluccio, F.

1964. Diccionario folklórico argentino. Edición popular: Buenos Aires, Luis Lasserre y Cía. Editores, 2 tomos, $510 \mathrm{pp}$.
De Ovalle, A.

1646. Histórica relación del reino de Chile. Santiago, Editorial Pehuén, 2003, 677 pp.

Del Pozo, J.

2014. Historia del vino chileno. Desde la época colonial hasta hoy. LOM Ediciones, Santiago, Chile, 306 pp.

Fernández Labbé, M.

2010. Bebidas alcohólicas en Chile. Una historia económica de su fomento y expansión 1870-1930. Santiago, Centro Barros Arana/Universidad Alberto Hurtado, 270 pp.

Gatica de Montiveros, M.D.

1995. Diccionario de regionalismos de la provincia de San Luis. San Luis, Fondo Editorial Sanluiseño. 414 pp.

Gay, C.

1973. Historia física y política de Chile. Tomo II: Agricultura. Santiago, Museo de Historia Natural, 1855. Edición moderna consultada: Santiago, Icira. 443 pp. 
González de Ortiz, A.E.

2006. Breve diccionario argentino de la vid y del vino. Estudio etnográfico lingüístico. Buenos Aires, Academia Argentina de Letras. $121 \mathrm{pp}$.

Le Feuvre, R.F.

1877. Informe sobre la enfermedad de las viñas presentado al Ministro de Hacienda. En: Boletín de la Sociedad Nacional de Agricultura, vol. VIII, 20 de marzo de 1877: 205-213.

Le Feuvre, R.F.

1884. Informe sobre el estado de las viñas en San Felipe, Los Andes, Mendoza, San Juan y Buenos Aires, En: Boletín de la Sociedad Nacional de Agricultura, vol. XV, 5 de junio de 1884: 334-347.

Le Feuvre, R.; Barros, L.; Ovalle, D.; Rojas, M.

1886. Exposición Departamental de Los Andes. Informe de la Comisión nombrada para estudiar dicha exposición". Boletín de la Sociedad Nacional de Agricultura, vol. XVIII, 5 de noviembre de 1886: 35-48.

Le Feuvre, R.F.

1890. Informe pasado al señor Ministro de Industria y Obras Públicas sobre el estado actual de la agricultura y muy especialmente de la viticultura en la provincia de Maule y los medios de fomentar estas industrias". Boletín de la Sociedad Nacional de Agricultura, vol. XXI, 20 de julio de 1890: 556-564.

\section{Menadier, J.}

1874. La vinicultura nacional. En: Boletín de la Sociedad Nacional de Agricultura, vol. VI, 5 de noviembre de 1874: 28-31.

Pardo, O.; Pizarro, J.L.

2005. La chicha en el Chile Precolombino. Santiago, Editorial Mare Nostrum, 127 pp.
Pereira, E.

2013. Apuntes para la historia de la cocina chilena. Santiago, Uqbar, 298 pp.

Pszczólkowski, P.

2014. Terroir y Climats: ¿realidad o quimera?. Revista Iberoamericana de Viticultura, Agroindustria y Ruralidad, (RIVAR), 1(1): 13-19.

Pszczólkowski, P.

2015. Sauvignon Blanc, Cabernet-Sauvignon y Carmenère, cepas claves de la viticultura actual de Chile. Revista Iberoamericana de Viticultura, Agroindustria y Ruralidad (RIVAR), 2(1): 1-15.

Pszczólkowski, $\mathrm{Ph}$.

2013. Carmenère, mayoría de edad: 1994-2012. Estudios Avanzados, 20:137-154.

Riveros, V.

1881. Memoria sobre el fundo de Quella perteneciente a la testamentaria del finado señor Juan Manuel Oñat. Santiago, Chile.

Rodríguez, Z.

1875. Diccionario de Chilenismos. Imprenta del Independiente. Santiago, Chile, 487 pp.

Rosales, Diego.

1674. Historia General del Reyno de Chile. Valparaíso, Imprenta del Mercurio, 1877, 506 pp.

Solar y Claro, J.M.

1890. Fabricación de la chicha cocida. Boletín de la Sociedad Nacional de Agricultura XXI (24) (Santiago, 20 de diciembre de 1890): 1058-1064.

\section{Notas}

1 Partición de bienes de Ramón Ramírez, Corcolón, 5 de noviembre de 1823. AN, Fondo Judiciales de San Fernando, Legajo 63, Pieza 14, foja 26v.

2 Tasación de bienes de don Francisco Prats, Santiago, 10 de julio de 1837. AN, Fondo Judiciales de Santiago, Legajo 177 , pieza 4 , foja $1 \mathrm{v}$.

3 Don Bernardo González con don Mateo Campos sobre cobre de pesos, Santiago, 1844. AN, Fondo Judiciales de Santiago, Pieza 9, foja 18.
El Diario Ilustrado, Santiago, 20 de septiembre de 1931, p. 1. El Diario Ilustrado, Santiago, 20 de septiembre de 1948, p. 9. El Diario Ilustrado, Santiago, 20 de septiembre de 1948, p. 9.

7 El Diario Ilustrado, Santiago, 20 de septiembre de 1950, p. 2.

8 El Mercurio, Santiago, 20 de septiembre de 1951, p. 11; El Diario Ilustrado, Santiago, 20 de septiembre de 1951, p. 1. 